\title{
Marital Orientation and Relationship Well-Being Among Cohabiting Couples
}

Brian J. Willoughby

Brigham Young University, brian.willoughby@byu.edu

Dallin Belt

Follow this and additional works at: https://scholarsarchive.byu.edu/facpub

Part of the Social and Behavioral Sciences Commons

\section{Original Publication Citation}

Willoughby, B. J., \& Belt, D.* (2016). Marital orientation and relationship well-being among cohabiting couples. Journal of Family Psychology, 30, 181-192.

\section{BYU ScholarsArchive Citation}

Willoughby, Brian J. and Belt, Dallin, "Marital Orientation and Relationship Well-Being Among Cohabiting Couples" (2016). Faculty Publications. 5141.

https://scholarsarchive.byu.edu/facpub/5141

This Peer-Reviewed Article is brought to you for free and open access by BYU ScholarsArchive. It has been accepted for inclusion in Faculty Publications by an authorized administrator of BYU ScholarsArchive. For more information, please contact ellen_amatangelo@byu.edu. 


\title{
Marital Orientation and Relationship Well-Being Among Cohabiting Couples
}

\author{
Brian J. Willoughby and Dallin Belt \\ Brigham Young University
}

\begin{abstract}
The aim of this study was to expand on previous studies of cohabitation to understand the relationship between marital orientations and the relationship well-being of cohabiting couples with a particular focus on using dyadic analyses to understand within-couple patterns. Results from a sample of 1,837 couples provided evidence that an intent to delay marriage and a lower importance placed on marriage for 1 partner was related to lower relationship well-being assessments for both partners in the areas of couple satisfaction, stability, and communication. Greater differences between partners in the intent to delay marriage and importance placed on marriage were also found to be associated with some outcomes. When female partners had a greater intention to marry or a greater importance placed on marriage than male partners, couples began to report lower assessments of couple well-being. Finally, whether or not a couple was engaged at the time of cohabitation moderated some of the findings, suggesting that some associations were stronger or only present among cohabiters that were not engaged. The findings of the study provide further evidence that cohabiting couples are not all the same and that marital orientations and engagement status are important indicators of relationship well-being for many such couples.
\end{abstract}

Keywords: cohabitation, marital beliefs, attitudes, romantic relationships, marriage

One of the most significant changes to the recent dating culture in the United States has been the dramatic increase in the rates of premarital cohabitation (Goodwin, Mosher, \& Chandra, 2010; Seltzer, 2004). Cohabitation now often precedes marriage (Goodwin et al., 2010) and over half of all young adult relationships include some form of cohabitation (Schoen, Landale, \& Daniels, 2007). Cohabiting couples are also accounting for an increasing proportion of births outside of marriage with over half of all nonmarital births now occurring within cohabiting unions (Curtin, Venture, \& Martinez, 2014). This increased prevalence of cohabitation has drawn considerable scholarly attention focused on understanding such unions.

Much of the scholarship on cohabitation focuses not on cohabiters themselves but on those who have cohabited in the past and have moved on to marriage (Jose, O'Leary, \& Moyer, 2010; Kline et al., 2004). This research has focused on heterogeneity between types of couples, often on how cohabiters are different than those in other types of unions. Although the literature is saturated with such explorations, much less attention has been placed on understanding the relational correlates of cohabiters currently within such relationships. This has led to an absence of scholarship concentrated not on how all cohabiters may differ from those in other relational statuses but on how intragroup differences among

This article was published Online First September 7, 2015.

Brian J. Willoughby and Dallin Belt, School of Family Life, Brigham Young University.

Correspondence concerning this article should be addressed to Brian J. Willoughby, School of Family Life, Brigham Young University, 2081 JFSB, Brigham Young University, Provo, UT 84602. E-mail: brian .willoughby@byu.edu cohabiters may help scholars understand the nature and potential dynamics of cohabiting relationships.

The current study sought to help expand this underdeveloped branch of scholarship and addresses this limitation by exploring variations in the relational well-being among cohabiting couples. Specifically, we focus on how marital orientations among cohabiters may help scholars understand relational differences within such relationships. Marital orientations are defined as how individuals think about marriage generally and toward their specific partner and were selected as a variable of interest as marital beliefs have been highlighted in several recent studies as a potential factor in determining variability among cohabiters (Light \& Omori, 2013; Willoughby, Carroll, \& Busby, 2012). Although few cohabiters may actually go on to marry their current partner, such scholarship has suggested that how cohabiters orient their current relationship toward a future marriage may be vital to current relational dynamics and well-being.

\section{Cohabitation and Marital Orientation}

Although cohabiters likely have similar relational dynamics in many ways compared with other committed couples, several elements of cohabitation provide a unique relational context for such partners. Perhaps the most obvious is the fact that many cohabiting couples are often situated in their relationship development between nonresidential dating and marriage. Although cohabiters may never transition to marriage (Schoen et al., 2007) or may utilize cohabitation as a substitute for legal marriage (Heuveline \& Timberlake, 2004), many heterosexual cohabiting individuals desire an eventual marriage (Guzzo, 2009) regardless of if that marriage is with one's current or future partner. Within the United States, long-term cohabitation is still rare (Light \& Omori, 2013) and less than a quarter of cohabiting relationships last more than 3 
years (Goodwin et al., 2010). In this way, cohabitation for many individuals is inherently a temporary status, either viewed as a stepping stone toward marriage with one's current partner or as a way to gain committed relationship experience when one is not ready or unwilling to make a transition to marriage. Perhaps due to the unique marital context of cohabitation for many U.S. couples, how such couples orient toward or away from marriage has become one of the most studied areas of recent cohabitation research.

Early attempts at understanding how one's orientation toward marriage may influence cohabiting dynamics focused on engagement status (Kline et al., 2004; Rhoades, Stanley, \& Markman, 2009; Stanley, Rhoades, Amato, Markman, \& Johnson, 2010). These studies generally found that cohabiters who were cohabiting preengagement reported more negative relational outcomes during marriage, whereas those who began cohabiting after engagement did not report such adverse effects. Rhoades, Stanley, and Markman (2009) called this a "preengagement cohabitation effect" and suggested that cohabiting preengagement may have a causal negative effect on eventual marriage through the accumulation of constraint commitments.

More recent studies have taken this idea further, suggesting that how individuals view an eventual marriage to their partner, often labeled as marital intentions, may alter current relational dynamics regardless of engagement status and regardless of if the couple actually marries (Murrow \& Shi, 2010; Willoughby et al., 2012). Additionally, research has found that couples who view cohabitation as a precursor to marriage tend to have higher relationship quality (Murrow \& Shi, 2010) and making plans to eventually marry has been associated with increases in relationship quality and stability among some cohabiters (Brown, 2004). Generally, such studies have shown that couples with clear intentions to marry their partner fare better than cohabiting couples who either disagree, have ambiguous plans, or no plans for marriage. However, several important limitations exist which hinder the practical utility of such findings.

As mentioned before, much of this scholarship has still explored engagement and marital orientations in the context of comparing past and current cohabiting couples to those in other types of unions. For example, Rhoades et al. (2009) explored the nature of engagement among married couples based on cohabitation history. The nature of such scholarship inherently ignores within-group variations among cohabiters. Despite the focus of some previous studies on cohabiting couples themselves, a surprising amount of this small body of research has not been conducted within a couple context. Willoughby, Carroll, and Busby's (2012) study of cohabiting couples implied that differences in marital plans may impact relational well-being but only tested this assumption at the individual level. Rhoades et al. (2009) likewise suggested that cohabitation occurring before or after clear marital plans impacted eventual marital outcomes, but such findings relied on individual and not couple reports. Despite marital orientations being identified as an important indicator of relational dynamics among cohabiters, such evidence has largely been based on retrospective data and at the individual level. It is currently unknown if the association between marital orientations and well-being among heterosexual cohabiting couples are strictly individual-level phenomenon or if cross-partner effects will exist.

Such cross-partner associations are likely of interest for two reasons. First, several relational scholars have called for the in- creased use of actor-partner interdependence models (APIM; Kenny \& Cook, 1999) to better understand relational well-being among all types of couples but few studies involving cohabitation have utilized them. Such analyses are based on ideas drawn from interdependence theory (Rusbult \& Ximena, 1997) which suggests that individual behavior and perceptions will be based partially on the influence of each partner on the other. Applied to the study of cohabiting couples, marital orientations may produce such crosspartner effects as such orientations are inherently linked and connected to one's partner. General and specific marital plans, regardless of if such plans involve or avoid future marriage, are likely communicated explicitly and implicitly between partners and each partner's perception of the relationship is likely partially influenced by interpreting the implicit and explicit messages their partner sends about marriage. Further, when couples disagree about future marital plans, such disagreements about the future of the relationship may undermine relationship health. Without dyadic analysis, however, it is impossible to know if associations in previous studies are static across partners or if unique withincouple patterns arise. Second, although research has suggested that women and men differ in regards to how they view marriage within cohabiting unions (Huang, Smock, Manning, \& BergstromLynch, 2011), it is unknown if male or female marital orientations have differing or similar impacts on the overall relationship. It is also unknown if differences among partners are related to decreased relational well-being among cohabiters as suggested by some scholars (Willoughby et al., 2012).

Another limitation of the current scholarship in this area is that it is unknown where the effect of marital orientations truly lies. Although both engagement status (Rhoades et al., 2009) and beliefs about marriage (Willoughby et al., 2012) have been highlighted as contributing factors, no study has attempted to parcel out the unique effect of both. In addition, although both specific intentions to marry one's partner (Brown, 2004) and generalized beliefs about marriage (Willoughby et al., 2012) have both been linked to relational well-being among cohabiters, no study has explored both types of marital orientations together to explore if either specific or generalized marital orientations have stronger links to relational well-being among cohabiters. Therefore, little is known regarding if engagement status, general beliefs, and relationally specific beliefs about marriage all uniquely contribute to relational dynamics among cohabiters.

To address these limitations, we sought within the current study to explore how the marital orientation and engagement status of each partner in a heterosexual cohabiting relationship may be associated with both their own and their partner's reports of relational well-being. In addition, the current study is the first to explore differences between partners in their orientations toward marriage to see if such differences are linked to relational wellbeing as suggested but not tested in previous studies.

\section{Theoretical Foundations}

We draw on two main theories to frame our analyses. The first is Inertia theory, first proposed by Stanley, Rhoades, and Markman (2006). Inertia theory is derived from commitment theory, which separates relationship commitment into two distinct areas: dedication and constraint commitment (Stanley \& Markman, 1992). Inertia theory proposes that in cohabiting relationships, a partial 
explanation for poor relationship outcomes among some cohabiters can be found in the concept of "sliding versus deciding" (Stanley, Rhoades, \& Markman, 2006) where couples that make explicit decisions to commit to each other often avoid the negative effects of imbalances between constraint and dedication commitment. As stated by Stanley and colleagues, "inertia cannot be the driving force to marry if the decision to marry was made before cohabitation" (p. 505). Indeed, a deliberate decision to marry, exemplified by engagement or clear marital plans, has been shown to be associated with positive relationship outcomes among cohabiters (Rhoades, Stanley, \& Markman, 2009; Stanley et al., 2010), greater confidence and interactions in the relationship (Kline et al., 2004), and lower risk of marital dissolution (Manning \& Cohen, 2012). Therefore, Inertia Theory helps explain the importance of exploring marital orientations by suggesting such beliefs are linked to underlying commitment and relational dynamics.

Although Inertia theory helps explain why martial orientation would be a unique relational indicator of cohabiting couples, it does not address how such effects may manifest. Another theoretical framework relevant to this line of research is Marital Paradigm Theory (Willoughby, Hall, \& Luczak, 2015). Willoughby and colleagues argued that how one orients toward marriage generally will shift specific intentions to engage in relational or individual behavior. Applied to cohabitation, Marital Paradigm Theory would suggest that martial orientations become an important frame of reference for cohabiters and likely shift intentions to engage in positive or negative relational behaviors. Those who have clear future plans with a cohabiting partner may be more likely to put personal resources and effort into seeing that relationship succeed (see Willoughby, 2015). Furthermore, cohabiting couples who hold differing paradigms about marriage may engage in conflictual dialogue about the future of the relationship or hold resentment toward their partner based on unfulfilled levels of commitment if one partner is unwilling to move toward marriage, suggesting that difference in marital orientations may lead to negative relational well-being.

Both of these theories highlight the importance of marital plans and commitment to the well-being of cohabiters. Ambiguity about the relationship is especially prevalent among cohabiters (Manning $\&$ Smock, 2005) as it could represent a precursor to marriage or an alternative to marriage (Heuveline \& Timberlake, 2004). If one partner places a high importance on marriage and intends to marry their partner but such feelings are not reciprocated by their partner, some relationships may continue despite decreased dedication commitment due to an accumulation of constraint commitments. However, as the relationship continues, this difference in marital paradigms may undermine well-being as each partner senses they have differing visions of the future and therefore engage in relational behavior based on different intentions.

\section{Current Study Purpose and Hypotheses}

We expand on previous scholarship by examining such associations between marital orientation and well-being to an actorpartner interdependence framework (Cook \& Kenny, 2005) while also examining the effect of cross-partner differences in marital orientations as differences across partners may have unique effects on relational outcomes (Willoughby et al., 2012). We selected three indicators of relational well-being (positive communication, stability, and satisfaction) that have been highlighted as important indicators of relational success (Busby, Holman, \& Taniguchi, 2001). We also explore the unique nature of engagement status given previous research suggesting that engaged cohabiters may have unique relational indicators compared with other types of cohabiting couples (Rhoades et al., 2009; Stanley et al., 2010). As previous research has been unclear if engagement status or marital orientations are truly the driver of relational dynamics among cohabiters, we explored if marital orientations predicted outcomes above and beyond the effect of engagement status. Some scholars have also suggested that engaged cohabiters may represent a unique couple type, different than other types of cohabiters (Rhoades et al., 2009; Willoughby et al., 2012). As engaged couples may have a clearer sense of marital trajectory, marital orientations and differences in such orientations may operate differently among such couples. As such, we also explored how engagement status may moderate associations between marital orientations and couple outcomes. As no previous research exists on cross-partner associations, we do not make specific directional hypotheses related to gender. However, we tested the following three hypotheses based on both previous empirical and theoretical findings:

Hypothesis 1 (H1): An intention to delay marriage and a lower importance placed on marriage generally among heterosexual cohabiters will be associated with less relationship satisfaction, less relationship stability, and less positive relationship communication for both male and female partners after controlling for engagement status.

Hypothesis 2 (H2): Greater differences in both the importance of marriage and the intention to delay marriage across male and female cohabiting partners will be associated with less relationship satisfaction, less relationship stability, and less positive relationship communication for both partners after controlling for engagement status.

Hypothesis 3 (H3): Engagement status will moderate associations between marital orientations (importance and intention to delay marriage) and relationship well-being indicators among cohabiting partners.

\section{Method}

\section{Procedure and Sample}

Participants for this study included 3,674 individuals who formed 1,837 unique mixed-sex heterosexual cohabiting couples from the United States. These couples were sampled across the United States and formed couple pairs who took the Relationship Evaluation Questionnaire (RELATE; further details found below) instrument online from 2006 until 2014 (Busby et al., 2001). The largest racial group was White (male: $80 \%$; female: $79 \%$ ) followed by Asian (male: $5 \%$; female: $7 \%$ ), Black (male: $5 \%$; female: $4 \%$ ), and Latino (male: 5\%; female: $4 \%$ ) participants. The largest religious denomination within the sample was Protestant (male: 26\%; female: $30 \%$ ). The original sample taken from RELATE does include an oversampling of couples who affiliate with the Church of Jesus Christ of Latter-day Saints (LDS). To alleviate this over- 
sampling, a random sample of LDS couples was taken from the original sample and retained for the current study. After this random sampling, LDS couples accounted for 3\% of the total sample. A small percentage of men (9\%) and $17 \%$ of females reported a yearly personal income of less than $\$ 20,000$ whereas $12 \%$ of men and $3 \%$ of women within the sample reported a personal yearly income of more than $\$ 140,000$. Seventy-four percent of male participants had completed some form of postsecondary degree whereas $81 \%$ of females had obtained such a degree. The average age of the sample was 31.37 years $(S D=7.21)$ for males and 29.26 years $(S D=6.21)$ for females. About $9 \%$ of couples had been together for less than 1 year, $33 \%$ had been together for 1 to 2 years, and the rest had been together for 3 or more years.

\section{Procedure}

All participants completed an appropriate consent form prior to the completion of the RELATE instrument and all data collection procedures were approved by the institutional review board at the authors' university. Individuals completed RELATE online after being exposed to the instrument through a variety of settings. The RELATE assessment is a couple assessment designed to assess and provide feedback to those in romantic relationships. After taking the RELATE, couples are provided with feedback on their relationship strengths and weaknesses. Some participants were referred to the online site by their instructor in a university class, others by a relationship educator or therapist, and some participants found the instrument by searching for it on the web. Participants were instructed to complete the assessment alone and to not discuss their responses with their partner. We refer the reader specifically to Busby Holman, and Taniguchi's (2001) discussion of the RELATE for detailed information regarding the theory underlying the instrument and its psychometric properties.

\section{Measures}

Marital orientation. Two measures of marital orientation were utilized to assess individual intentions to marry one's current partner and the importance of marriage. The first item asked the individual "How long will it be from now until you and your partner marry?" with each respondent asked to select a response representing their intention. This item was then coded so higher responses would indicate a later intention to marry, or an intention to delay marriage. Responses ranged from 1 (less than 3 months) to 6 (we plan to marry but have no definite plans/we have no plans to marry). On average across the whole sample, men reported significantly, $t=-7.11, p<.001$ less intention to delay marriage $(M=2.97, S D=1.73)$ than women $(M=3.08, S D=1.83)$. Marital importance was assessed by asking each individual to indicate their agreement with the statement "Being married is among the one or two most important things in life" using a 5 -point scale $(1=$ strongly disagree to $5=$ strongly agree $)$. Single-item indicators of marital importance have been shown to be consistent and valid predictors of outcomes in previous studies (Willoughby et al., 2015). The average importance of marriage for men $(M=3.55, S D=1.09)$ was similar, $t=-1.02, p=.31$ to the average importance of marriage for women $(M=3.57, S D=$ 1.12). A difference score was then created between the male and female partner in each couple for both the intention to delay and marital importance measures with a positive difference indicating a higher score for the female than the male (difference score = female score - male score). On average, women had a greater intention to delay marriage than their male partners $(M=.11$, $S D=.91)$, but placed a greater overall importance on marriage $(M=.02, S D=1.41)$.

Couple outcomes. Three measures of couple well-being were used to assess individual satisfaction with the relationship, individual perception of the stability of the relationship, and positive communication. Separate scores were obtained for male and female partners. Relationship satisfaction was assessed with seven items asking participants how satisfied they were with various aspects of their relationship (e.g., in their sexual relationships and with the overall relationship). Items were rated on a 5-point scale $(1=$ very dissatisfied to $5=$ very satisfied $)$. Cronbach's alpha was in the acceptable range (male: $\alpha=.84$; female: $\alpha=.84$ ). Both men and women generally reported high satisfaction levels (male: $M=3.96, S D=.66$; female: $M=3.96, S D=.70)$. The RELATE satisfaction measures employed in this study have shown testretest reliability (between .76 and .78) and validity data have shown that this scale is highly correlated with an existing relationship satisfaction and quality scale (Revised Dyadic Adjustment Scale; Busby, Holman, \& Niehuis, 2009; Busby et al., 2001).

Relationship stability was assessed by averaging three items, which asked participants how often the following three things had happened in their relationship: "How often have you thought your relationship (or marriage) might be in trouble?," "How often have you and your partner discussed ending your relationship (or marriage)?," and "How often have you broken up or separated and then gotten back together?" Responses ranged from 1 (never) to 5 (very often). These items were reverse coded so that higher scores indicated more stability. Similar to scores on satisfaction, men and women within the dataset both generally reported high stability levels (male: $M=4.18, S D=.70$; female: $M=4.16, S D=.72$ ). These items were adapted from earlier work by Booth, Johnson, and Edwards (1983). Cronbach's alpha was in the acceptable range (male: $\alpha=.78$; female: $\alpha=.78$ ). Previous studies have shown this scale to have test-retest reliability values between .78 and .86 , to be correlated with other relationship quality measures, and to be valid for use in cross-sectional research (Busby et al., 2009; Busby et al., 2001).

Positive communication was assessed by asking participants five items relating to their overall communication patterns and ability to communicate clearly. Sample items included: "I talk over pleasant things that happen during the day when I am with my partner," "When I talk to my partner I can say what I want in a clear manner," and "I sit down with my partner and just talk things over." Responses were measured on a 5-point scale $(1=$ never to $5=$ very often $)$. In terms of test-retest and validity information on this scale, the communication items have been shown to have test-retest values between .70 and .83 and were appropriately correlated with a version of a commonly used Relationship Quality measure as predicted (Busby et al., 2001). Also this scale has been shown in longitudinal research to be predictive of couple outcomes and are amenable to change in couple intervention studies that focus on communication. Cronbach's alpha was again in the acceptable range (male: $\alpha=.89$; female: $\alpha=.90$ ). 


\section{Controls}

Given that socioeconomic status and relationship length likely impact relationship dynamics, the educational attainment of both partners and length of the relationship were utilized as controls in all analyses. Educational attainment was based on one item asking each participant the farthest educational milestone they had achieved. Responses ranged from 1 (less than high school) to 9 (graduate or professional degree completed). Relationship length was assessed by one item asking each couple: "How long have you and your partner been dating?" Responses ranged from 1 ( 0 to 3 months) to 11 (more than 40 years).

\section{Data Analysis}

Data analyses were conducted utilizing structural equation models (SEM) and utilized Mplus version 7 software. For models exploring actor-partner effects, analytic procedures followed those recommended by Cook and Kenny (2005). First, dependency between partner scores was examined and strong evidence for such dependency existed (as one illustration, bivariate correlations between male and female partner's stability scores across the sample were very high; $r=.74, p<.001$ ). Intraclass correlations (ICC) were also examined and provided further evidence of dependency. For example, the ICC for the male and female partner stability ratings was .85 , further suggesting dependence of scores. Having established dependency, SEM models were examined that controlled for underlying couple dependency and allowed individual partner's marital orientation scores to predict both their own relationship well-being scores (actor effects) and their partner's relationship well-being scores (partner effects). Overall model fit statistics were examined, including model chi-square statistics, the comparative fix index (CFI), root mean square error of approximation (RMSEA), and standardized root-mean-square residual (SRMR). Models were considered good fit if the model $\chi^{2}$ statistic was not significant, CFI was greater than .90, RMSEA was less than .08, and SRMR was less than .08, although it was noted that $\chi^{2}$ statistics are sensitive to large sample sizes (Wang \& Wang, 2012). When significant, post hoc simple slopes tests were conducted to explore the nature of significant interactions. Missing data for SEM analyses utilized full maximum-likelihood estimators.

\section{Results}

\section{Marital Orientation and Cross-Partner Outcomes}

Table 1 includes means, standard deviations, and bivariate correlations among main study variables. Actor-partner structural equation models predicting male and female relationship wellbeing from male and female marital orientations were run controlling for engagement, relationship length, and male/female education to test hypothesis one. Results are depicted in Figure 1 and Table 2. Overall the model demonstrated adequate model fit, $\chi^{2}(555)=3242.70, p<.001 ;$ RMSEA $=.051$ CFI $=.91 ;$ $\mathrm{SRMR}=.06$. When examining specific path coefficients, several significant findings were found, including several partner effects. Generally it was found that an intention to delay marriage to one's partner was significantly associated with a report of lower relationship well-being. An intention to delay marriage to one's partner among males was significantly associated with several selfreported negative relational outcomes including less positive male communication $(\beta=-0.12, p=.021)$, less female stability $(\beta=-0.10, p=.037)$, and lower male satisfaction $(\beta=-0.13$, $p=.007)$. Standardized path coefficients within structural equation models can be used to gauge the effect size of direct effects and here suggested small effects. To further understand the practical utility of these effects, outcome variables were explored at \pm 1 $S D$ from the sample mean on male intent to marry. Generally,

Table 1

Sample Demographics, Means, and Standard Deviations

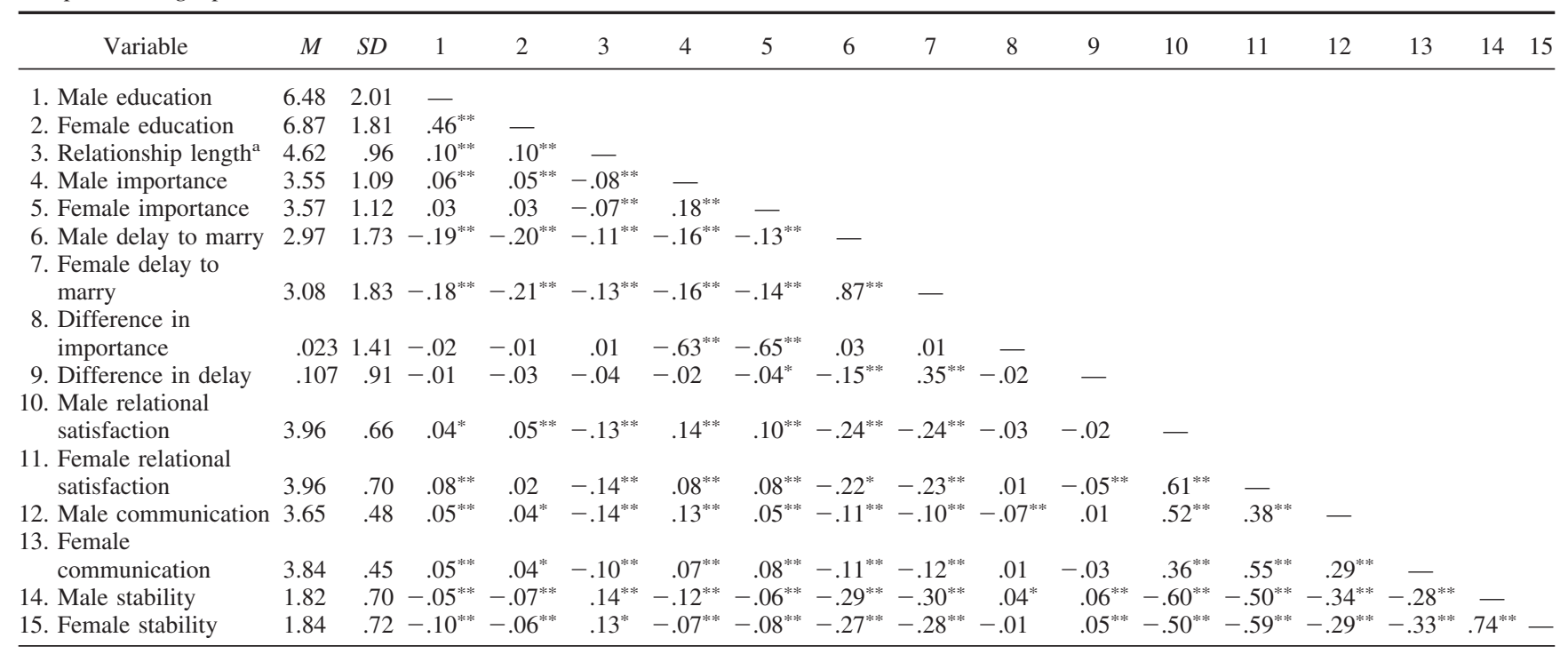

${ }^{\text {a }}$ Responses ranged from 1 ( 0 to 3 months) to 11 (more than 40 years).

${ }^{*} p<.05 .{ }^{* *} p<.01$. 


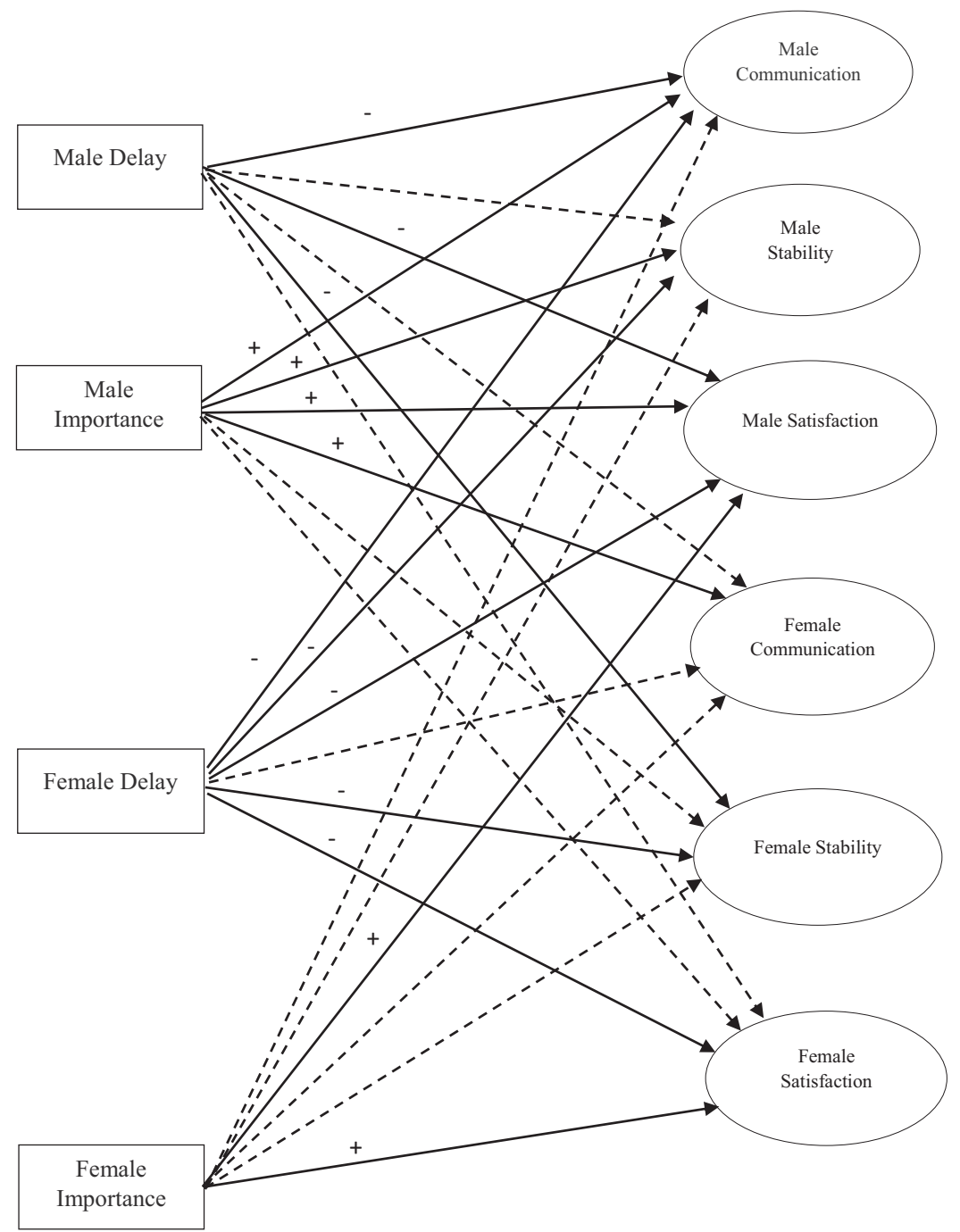

Figure 1. Actor-partner structural model predicting relationship well-being from male and female partner marital intentions and beliefs. Solid lines represent significant associations $(p<.05)$. \pm indicate directionality of association. Models include the following controls: male education, female education, relationship length. Only direct pathways between exogenous and endogenous latent variables shown.

these results suggested that individuals on the high end of intention to marry reported outcomes roughly a half-point higher on outcomes variables compared to those on the low end of intention to marry (male communication: $-1 S D=3.69$, $+1 S D=3.51$; female stability: $-1 S D=4.38,+1 S D=3.67$; male satisfaction: $-1 S D=4.13,+1 S D=3.53$ ).

Results for female partner's intention to delay marriage followed a similar pattern. A greater intention to delay marriage to one's partner among females was significantly associated with less stability among both male $(\beta=-0.24, p<.001)$ and female $(\beta=-0.21, p<.001)$ partners, lower male satisfaction $(\beta=-0.13, p=.012)$, lower female satisfaction $(\beta=-0.24, p<$ $.001)$, and less female positive communication $(\beta=-0.13, p=$ .015). Again comparing those on the high and low end of our female intention to delay marriage scale, results suggested a roughly half-point increase in positive outcomes for those on the low end of intention to delay marriage (male stability: $-1 S D=$ 4.37, $+1 S D=3.62$; female stability: $-1 S D=4.39$, $+1 S D=$ 3.66; male satisfaction: $-1 S D=4.14,+1 S D=3.62$; female communication: $-1 S D=3.87$, $+1 S D=3.70$ ).

Examining associations with the importance placed on marriage for both partners produced slightly different results. For male partners, increased belief in the importance of marriage was significantly associated with more positive male $(\beta=0.13, p<.001)$ and female $(\beta=0.07, p=.012)$ communication, more male stability $(\beta=.0 .08, p=.001)$, and higher male satisfaction $(\beta=$ $0.14, p<.001)$. Results at $\pm 1 S D$ on the importance scale for males again showed a roughly less than half-point shift in outcomes (male communication: $-1 S D=3.51$, $+1 S D=3.78$; female communication: $-1 S D=3.71,+1 S D=3.91$; male stability: $-1 S D=3.94,+1 S D=4.38$; male satisfaction: -1 $S D=3.76,+1 S D=4.23)$. The importance females placed on 
Table 2

Structural Coefficients (Standardized) for Models Predicting Male and Female Relational Well-Being

\begin{tabular}{|c|c|c|c|c|c|c|c|c|c|c|c|c|}
\hline \multirow[b]{2}{*}{ Variables } & \multicolumn{2}{|c|}{$\begin{array}{c}\text { Male } \\
\text { satisfaction }\end{array}$} & \multicolumn{2}{|c|}{ Male stability } & \multicolumn{2}{|c|}{$\begin{array}{c}\text { Male } \\
\text { communication }\end{array}$} & \multicolumn{2}{|c|}{$\begin{array}{l}\text { Female } \\
\text { satisfaction }\end{array}$} & \multicolumn{2}{|c|}{$\begin{array}{l}\text { Female } \\
\text { stability }\end{array}$} & \multicolumn{2}{|c|}{$\begin{array}{c}\text { Female } \\
\text { communication }\end{array}$} \\
\hline & $\beta$ & $S E$ & $\beta$ & $S E$ & $\beta$ & $S E$ & $\beta$ & $S E$ & $\beta$ & $S E$ & $\beta$ & $S E$ \\
\hline Actor-partner model & \multicolumn{12}{|c|}{$\chi^{2}(555)=3242.70^{* *} \mathrm{RMSEA}=.05 \mathrm{CFI}=.91 \mathrm{SRMR}=.06$} \\
\hline Engaged & .06 & .03 & $.09^{* * *}$ & .03 & -.01 & .03 & .04 & .03 & $.08^{* *}$ & .03 & -.01 & .03 \\
\hline Male marital delay & $-.13^{* *}$ & .05 & -.07 & .05 & $-.12^{*}$ & .05 & -.05 & .05 & $-.10^{*}$ & .05 & -.03 & .05 \\
\hline Female marital delay & $-.13^{*}$ & .05 & $-.24^{* * *}$ & .05 & -.04 & .05 & $-.24^{* *}$ & .05 & $-.21^{* * *}$ & .05 & $-.13^{*}$ & .05 \\
\hline Male marital importance & $.14^{* *}$ & .03 & $.08^{* * *}$ & .02 & $.13^{* *}$ & .03 & .04 & .02 & .00 & .02 & $.07^{*}$ & .03 \\
\hline Female marital importance & $.05^{*}$ & .03 & .03 & .02 & .02 & .03 & $.05^{*}$ & .02 & .04 & .02 & .04 & .03 \\
\hline Differences model & \multicolumn{12}{|c|}{$\chi^{2}(525)=2638.63^{* * *} \mathrm{RMSEA}=.05 \mathrm{CFI}=93 \mathrm{SRMR}=.04$} \\
\hline Engaged & $.25^{* *}$ & .03 & $.31^{* * *}$ & .02 & $.12^{* *}$ & .03 & $.24^{* * *}$ & .02 & $.30 * *$ & .02 & $.11^{* * *}$ & .03 \\
\hline Differences in marital delay & -.01 & .02 & $-.05^{*}$ & .02 & .01 & .03 & $-.06^{*}$ & .02 & -.04 & .02 & .03 & .03 \\
\hline Differences in marital importance & $-.06^{* *}$ & .02 & -.04 & .03 & $-.06^{*}$ & .03 & .01 & .02 & .01 & .02 & .03 & .03 \\
\hline \multicolumn{13}{|l|}{ Interaction models } \\
\hline Actor-partner model & \multicolumn{12}{|c|}{$\chi^{2}(669)=2814.06^{* * *}$ RMSEA $=.04 \mathrm{CFI}=.93 \mathrm{SRMR}=.03$} \\
\hline MDelayXEngage & -.10 & .09 & $-.24^{* * *}$ & .09 & $-.20^{*}$ & .10 & -.09 & .09 & -.09 & .09 & -.05 & .10 \\
\hline FDelayXEngage & $.29^{* *}$ & .10 & .19 & .10 & .17 & .11 & $.24^{*}$ & .10 & -.02 & .10 & .11 & .11 \\
\hline MImportanceXEngage & .07 & .10 & -.01 & .10 & -.13 & .11 & -.00 & .10 & -.02 & .10 & -.04 & .11 \\
\hline FImportanceXEngage & -.03 & .10 & -.07 & .10 & .15 & .10 & .01 & .10 & .13 & .10 & -.02 & .10 \\
\hline Differences Model & \multicolumn{12}{|c|}{$\chi^{2}(573)=2700.74^{* *}$ RMSEA $=.05 \mathrm{CFI}=.92 \mathrm{SRMR}=.04$} \\
\hline DelayXEngage & $-.22^{* *}$ & .03 & $-.28^{* * *}$ & .03 & $-.17^{* *}$ & .03 & $-.24^{* *}$ & .03 & $-.27^{* *}$ & .03 & $-.14^{* *}$ & .03 \\
\hline ImportanceXDelay & $.23^{* * *}$ & .05 & .10 & .05 & $.15^{\text {*** }}$ & .05 & .08 & .05 & .02 & .05 & .10 & .05 \\
\hline
\end{tabular}

Note. Other control variables not shown but included: relationship length, male education, and female education. RMSEA $=$ root mean square error of approximation; $\mathrm{CFI}=$ comparative fit index; SRMR $=$ root-mean-square residual.

${ }^{*} p<.05 .{ }^{* *} p<.01$.

marriage was significantly associated with higher female satisfaction $(\beta=0.05, p=.033)$ and with higher male satisfaction $(\beta=$ $0.05, p=.049)$. Differences explored across $\pm 1 S D$ on the importance scale for females suggested only small variations in outcome measures (female satisfaction: $-1 S D=3.90,+1 S D=$ 4.08; male satisfaction: $-1 S D=3.83,+1 S D=4.09)$. All results continued to suggest small effect sizes.

Overall the model predicted roughly $10 \%$ of the variance in most relational well-being indicators (male satisfaction: $R^{2}=.11$; female satisfaction: $R^{2}=.10$; male stability: $R^{2}=.12$; female stability: $R^{2}=.11$; male communication: $R^{2}=.06$; female communication: $\left.R^{2}=.04\right)$. Generally, results provided partial support for H1.

As data were cross-sectional, we also tested competing models where couple well-being indicators were used to predict marital orientations. These models included identical controls. Model fit was compared with the originally proposed model via chi-square difference tests to explore which model fit the data better. This alternative model was a good fit for the data, $\chi^{2}(561)=2338.42$, $p<.001 ; \mathrm{RMSEA}=.041 ; \mathrm{CFI}=.95 ; \mathrm{SRMR}=.06$. A chi-square difference test between the two models was significant, $\chi^{2}(6)=$ $904.28, p<.001$ and based on chi-square statistics, the alternative model was a slightly better fitting model. In this model, a greater intention among females to delay marriage was predicted by less male stability $(\beta=-.14, p=.02)$ and less female satisfaction $(\beta=-.12, p=.048)$. A higher importance placed on marriage by male partners was predicted by lower female stability $(\beta=-.13$, $p=.04)$ and higher male satisfaction $(\beta=.21, p=.008)$. Female importance of marriage and male intention to delay marriage were not significantly predicted by relational well-being and dynamic scores. In this alternative model, engagement status was a strong predictor of marital orientation, particularly male $(\beta=-.59, p<$ $.001)$ and female $(\beta=-.62, p<.001)$ intention to delay marriage.

\section{Differences in Intentions and Outcomes}

A second structural equation model was set up to explore associations between differences in the intention to delay marriage and the importance of marriage among partners and relational well-being, testing H2. Engagement, male and female education, and relationship length were utilized as controls. The overall model was an adequate fit for the data, $\chi^{2}(525)=2638.63, p<$ $.001 ;$ RMSEA $=.05 ; \mathrm{CFI}=.93 ; \mathrm{SRMR}=.04$, and in this model engagement status was a strong predictor of relationship outcomes. Full model results are shown in Figure 2 and Table 2. It was found that female partners' intention to delay marriage longer than their male partner (higher scores on the difference measure) was significantly associated with less male stability $(\beta=-0.05, p=$ $.026)$ and less female satisfaction $(\beta=-0.06, p=.023)$. Results suggested small effects. The practical implication of such associations were explored by considering outcome scores at $\pm 1 S D$ on the difference variable. Again, a roughly half-point drop on the outcome scale was observed moving from $-1 S D$ to $+1 S D$ on the difference variable (male stability: $-1 S D=4.03,+1 S D=3.64$; female satisfaction: $-1 S D=3.97,+1 S D=3.56$ ).

Differences in the importance placed on marriage were also associated with negative relationship well-being but only among male partners. A greater importance being placed on marriage by female partners compared to their male partners was significantly associated with less male partner satisfaction $(\beta=-0.06, p=$ .008 ) and positive communication $(\beta=-0.06, p=.012)$. Explo- 


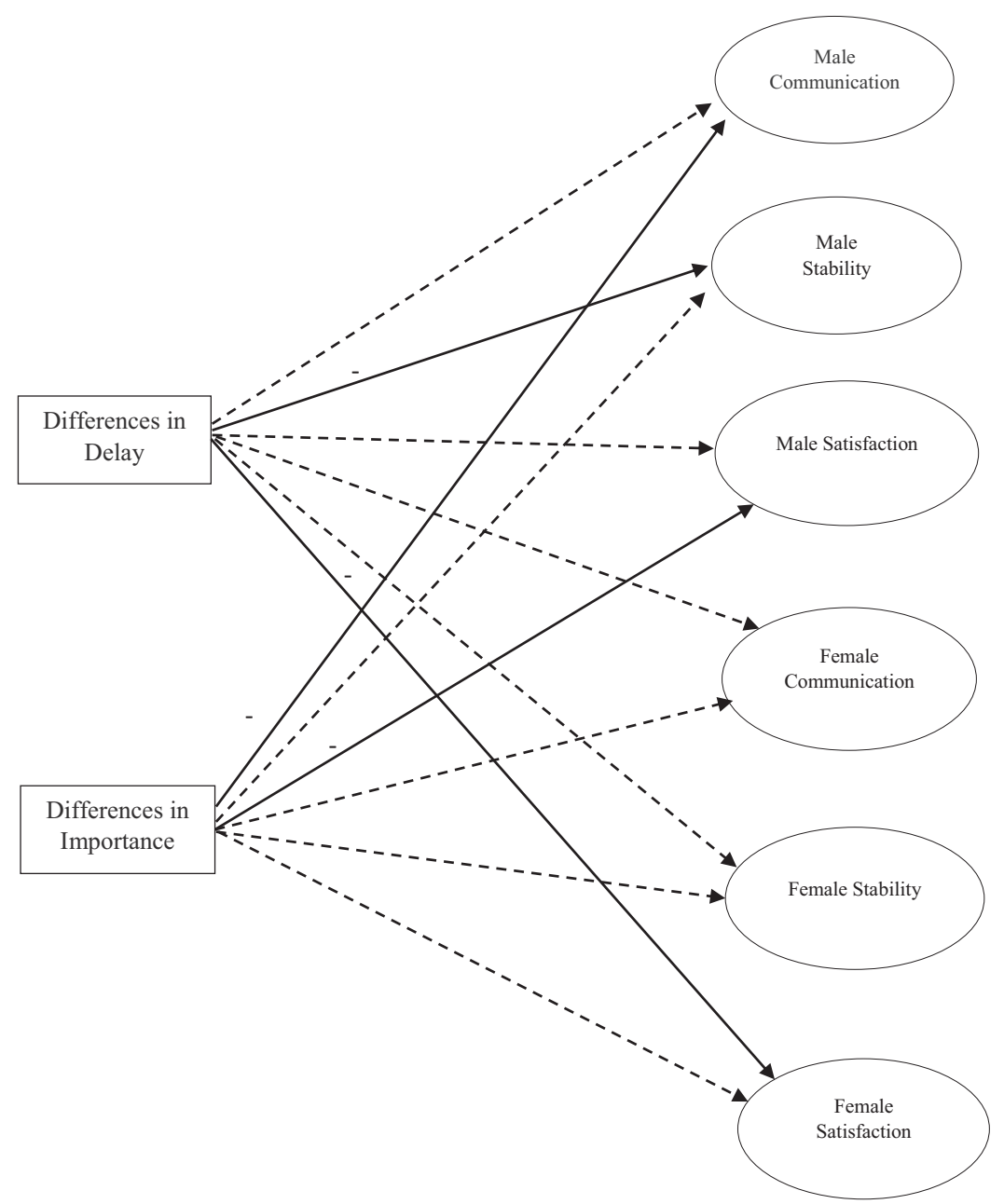

Figure 2. Structural model of associations between male and female relational well-being and differences in marital intent and importance. Solid lines represent significant associations $(p<.05)$. \pm indicate directionality of association. Models include the following controls: male education, female education, relationship length. Only direct pathways between exogenous and endogenous latent variables shown.

ration of outcomes at $\pm 1 S D$ on the difference measures suggested little practical movement on the outcomes variables suggesting such findings for the difference in importance may have less practical utility (male satisfaction: $-1 S D=3.94,+1 S D=3.85$; male communication: $-1 S D=3.66,+1 S D=3.63$ ).

Variance explained was generally lower in the difference model with the model explaining about $5 \%-10 \%$ of the variance in most relationship well-being indicators (male satisfaction: $R^{2}=.09$; female satisfaction: $R^{2}=.09$; male stability: $R^{2}=.13$; female stability: $R^{2}=.12$; male communication: $R^{2}=.05$; female communication: $\left.R^{2}=.04\right)$. This provided partial support for $\mathrm{H} 2$.

Again, an alternative model was tested where differences in marital orientations were predicted based on relational well-being and dynamics. This new model fit the data well, $\chi^{2}(549)=$ 2948.28, $p<.001 ;$ RMSEA $=.049 ; \mathrm{CFI}=.92 ; \mathrm{SRMR}=.05$, but based on chi-square difference test, $\chi^{2}(24)=309.65, p<.001$, the originally proposed model was a better fit for the data. As a further test of if differences were truly linked to relational outcomes, another alternative regression model was tested where male and female baseline marital orientations were controlled for. This model showed the same pattern of results as presented and full results of this post hoc analysis are available from the first author upon request.

\section{Moderation by Engagement Status}

Finally, to test hypothesis three, possible moderation by the engagement status of the couple was examined by adding engagement status (yes/no) by marital orientation interaction terms to the final models. Interactions were tested between engagement status and both marital orientation items (intention to delay/importance of marriage) for the prediction of all relational outcomes (see Table 2). For the main actor-partner model, the interaction model produced adequate fit, $\chi^{2}(669)=$ 2814.06, $p<.001$; RMSEA $=.04$; CFI $=.93$; SRMR $=.03$ Significant interactions were found between engagement status and male intention to delay marriage when predicting male positive communication $(\beta=-0.20, p=.04)$ and male sta- 
bility ( $\beta=-0.24, p=.007)$. Significant interactions between engagement status and female intention to delay marriage were found when predicting male $(\beta=0.29, p=.005)$ and female $(\beta=0.24, p=.02)$ satisfaction. Post hoc simple slopes analyses were then conducted for those who were engaged and not engaged. For the interactions with male partner's intention to delay marriage, it was found that such an intention was associated with less male positive communication for engaged $(\beta=-0.11, p<.001)$ and nonengaged $(\beta=-0.14, p=.007)$ couples but the effect was slightly stronger for the nonengaged. For male stability the differences were more pronounced. For engaged couples, an intention to delay marriage among men was associated with less male stability $(\beta=-0.23, p<.001)$ but no association was found for those not engaged $(\beta=-0.06$, $p=.19$ ).

For the interactions with female partner's intention to delay marriage, it was found that such an intention was significantly associated with less relationship satisfaction for men among those not engaged $(\beta=-0.22, p<.001)$ and engaged $(\beta=-0.17, p<$ $.001)$ but the effect was stronger among those who were not engaged. The same pattern was found for female satisfaction in that female partner's intention to delay marriage was associated with less relationship satisfaction among the not engaged $(\beta=-0.22, p<.001)$ and engaged $(\beta=-0.18, p<.001)$ but the effect was stronger among those not engaged.

Interactions in the difference model were also significant and pronounced, $\chi^{2}(573)=2700.74, p<.001$; RMSEA $=.045$; $\mathrm{CFI}=.92 ; \mathrm{SRMR}=.04$. A significant interaction between the difference in intention to delay marriage and engagement status was found when predicting all outcomes including male communication $(\beta=-0.17, p<.001)$, female communication $(\beta=-0.14, p<.001)$, male stability $(\beta=-0.28, p<.001)$, female stability $(\beta=-0.27, p<.001)$, male satisfaction $(\beta=-0.22, p<.001)$, and female satisfaction $(\beta=-0.24$, $p<.001)$. Post hoc simple slopes analyses for all outcome variables suggested that many interactions were not practically meaningful as no significant associations were found in post hoc tests. This was the case for the prediction of male communication, female communication, female stability, male satisfaction, and female satisfaction. For the prediction of male stability, having a female partner intend to delay marriage more than her male partner was related to significantly less male stability only among the not engaged $(\beta=-0.10, p=.03$; engaged: $\beta=-0.02, p=.44$ ).

Significant interactions were found between differences in the importance of marriage and male communication $(\beta=0.15, p=$ $.007)$ and male satisfaction $(\beta=0.23, p<.001)$. For the prediction of male communication, having a female partner place a greater importance on marriage than her male partner was significantly related to less positive male communication for both those who were engaged $(\beta=-0.06, p=.018)$ and not engaged $(\beta=-0.19, p<.001)$ but the effect was stronger among the not engaged. For the prediction of male satisfaction, having a female partner place a stronger importance on marriage than her male partner was significantly related to less male satisfaction only for those who were engaged $(\beta=-0.06, p=.034$; not engaged: $(\beta=-0.06, p=.155)$. Such results provided support for $\mathrm{H} 3$, particularly within the difference model.

\section{Discussion}

As the first study that has explored the specific cross-partner associations between marital orientations and relational well-being among cohabiters, results suggested that an intention to delay marriage to one's partner and less general importance placed on marriage were both associated with lower reports of relationship well-being. These findings support earlier research that suggests that cohabiting couples with clear marital trajectories often report better relational outcomes than couples with less clear pathways to marriage (Brown, 2004; Murrow \& Shi, 2010; Willoughby et al., 2012). It should be noted that such associations were found after controlling for engagement status. In fact, in the presence of specific marital orientations within the model, engagement status was only significantly related to relational stability for both partners.

The findings from the current study also expand on previous findings by showing that associations between marital orientations and relational well-being not only occur individually, but relationally. Several cross-partner associations were found where male and female orientations toward marriage were significantly associated with their partner's reports of relational well-being, with some associations altering based on gender. For example, the importance placed on marriage by females did not appear to have strong cross-partner effects, only being weakly associated with one male well-being indicator. The intention to delay marriage by women on the other hand had significant cross-partner associations with both male satisfaction and male stability. The importance male partners placed on marriage was significantly related to female positive communication whereas the intention to delay marriage among male partners was significantly related to stability as reported by female partners. Although follow-up analyses suggested that such effects were small in nature, these results suggest that the associations between marital orientation and relationship well-being are likely relational in nature, influencing both partners and not being limited to simply within-person variations.

Such findings could be caused by several possible factors. It should first be noted that due to the cross-sectional nature of the data collected for the current project, directional causation between marital orientation and relational well-being is unclear. As noted in the results, some evidence exists for an alternative model tested where marital orientations are predicted by relational well-being. On one hand, it is possible that those who have a stronger and more positive orientation toward marriage put more relational effort and resources into their current relationship. Marital Paradigm Theory (Willoughby et al., 2015) would suggest such investments would occur, as would research linking marital beliefs to relational effort (Willoughby, 2015). As individuals place a higher priority on marriage, they may be more likely to invest in their premarital cohabiting relationships. Such investments and associated relational effort has been shown in previous research to correlate to more positive relationship development (Wilson, Charker, Lizzio, Halford, \& Kimlin, 2005). However, it is also possible that negative relationship dynamics and assessments may alter an individual's marital orientation both in terms of their current relationship and in general. Some studies have now suggested that marital beliefs are malleable and shift based on life experience (see Willoughby, 2010). Negative relationship experiences with one's partner may shift one's orientation away from marriage. In reality, 
both such mechanisms are likely at play in a reciprocal relationship with couple dynamics. Cohabiting relationships are likely influenced by baseline marital orientations and such orientations may then shift across time based on one's self-perception and evaluation of the relationship. An important next step in this line of research is to explore such associations longitudinally to begin to understand how cohabiting couples navigate relationship dynamics and future expectations as both shift dynamically across time. Regardless of directionality, these findings underscore that marital orientations are a component of cohabiting couples' well-being.

Results exploring difference scores also hold important implications for scholarship on cohabiting couples. Although the men and women across the sample did not differ substantially in their marital orientations, specific differences between partners appear to be related to relational outcomes. In line with research suggesting that ambiguity in marital orientation is negatively associated with relationship outcomes among cohabiting couples (Willoughby et al., 2012), results of the current study suggested that differences in both the intention to delay marriage and the general importance placed on marriage were associated with negative relational well-being among cohabiters. Specifically, when female partners intended to delay marriage longer than their male partners, male partners reported significantly lower levels of relationship stability and female partners reported significantly less satisfaction. However, these relationships were moderated by engagement status and effect sizes were generally smaller among difference variables than direct effects between marital orientations and outcomes. This was also the case for results exploring differences in general marital importance. A greater importance placed on marriage by female partners compared with their male partners was associated with lower reports of male satisfaction and positive communication but results were again heavily moderated by engagement status. In most cases, associations between differences in marital orientations and relational well-being were either stronger or only found among the nonengaged.

Such moderation within the difference model replicates the previously found importance of engagement status when discussing cohabitation (Kline et al., 2004; Rhoades et al., 2009; Stanley et al., 2010). Although associations between individual marital orientations and individual reports of relationship well-being were largely consistent across engagement status, differences between partners appear to be a stronger concern among those who are not engaged. Although merely speculative at this point, it may be that being engaged reduces couple tension around differing marital orientations as engagement itself implies a degree of forward trajectory toward marriage. Whereas engaged couples may disagree on the importance of an impending marriage or the pace at which they are planning a wedding, this implicit movement forward may mitigate unhealthy relationship patterns from forming. Although this may again suggest the importance of having a clear relational trajectory for cohabiting couples in terms of healthy outcomes, more generally it suggests that further research should continue to examine the unique role of engagement among cohabiting couples when partners have differing orientations toward a future marriage. Findings of the current study and previous research continue to suggest that engaged cohabiting couples may be unique compared with other cohabiting couples in terms of both their dynamics and well-being trajectories. Much additional work is needed to understand the nature of engagement for both cohabiting and noncohabiting individuals.

For those cohabiting couples who are not engaged, these associations could again be bidirectional. It is possible that differences in marital trajectory create conflict among nonengaged cohabiting couples regarding the future direction of the relationship. It is also possible that an unstable and unsatisfying relationship undermines one's intention to marry one's partner. As the actor-partner model likewise suggested that female marital intention had a stronger relationship with male and female stability scores than an intention for delay among men, it appears from the current results that a female's intention to marry may be particularly important to the underlying stability of cohabiting relationships. Given that these associations were among the strongest found in the present study, this represents an important new finding that merits further study.

Generally results also have implications and connections to Inertia theory (Stanley et al., 2006) as related to cohabiting couples. Stronger importance being placed on marriage generally has been associated with stronger individual commitment among those in relationships (Willoughby, 2015). Thus, although not directly measured in the current study, we can assume that when female partners value marriage generally more than their male partners, they also may have stronger commitment to their specific partners or more hope that their particular relationship may move toward marriage. However, as all couples in the current study were still in an ongoing relationship, it is possible that men in such discrepant relationships are staying in the relationship due to the presence of constraint commitments. This sets up a relational scenario where female partners are pushing for or placing greater importance on a marriage to a male partner who is reluctant to move forward and potentially staying in the relationship due to constraints. This would explain the lower male satisfaction and communication scores when female partners place higher importance on marriage than their male partners. Given that over a third of the sample included a female partner who placed more importance on marriage than their male partner, such a finding may help shed light on previous findings linking cohabitation to constraint commitment. This suggests that scholars should pay particular attention to how some cohabiting couples who transition to marriage may involve a less committed male partner and a female partner who has a much stronger commitment to marriage. It also highlights that studies should explore if cohabiting couples with differing levels of marital importance report discrepant levels of constraint commitment. Scholars should also explore how the magnitude of differences may be associated with relational health as the current study only focused on continuous differences.

Several limitations should be acknowledged as to not overgeneralize the results of the current study. First, as already noted, associations in the current study were cross-sectional and care should be taken to not assume causal directions between marital orientations and relational well-being based on the results of the current study. Also, effect sizes were generally small for most associations, as is common with previous research on marital beliefs. Follow-up analyses suggested that within the current sample, relational well-being varied by approximately a half point on relational outcome scales based on shifts in marital orientations. Marital orientations are likely only one component of what makes healthy or unhealthy relationships, even among cohabiting couples. Although such an association should not be ignored given its 
strong replication in recent years, scholars and practitioners should be cautious as to not overstate its importance as many factors contribute to determining a couple's overall relational health.

We also note that the sample used here, although national in scope, is limited in its ability to generalize to certain segments of the population. This is perhaps most true of cohabiting couples reporting a lower socioeconomic status. Scholars have noted that such cohabiting couples are likely unique when compared to middle-class cohabiters in terms of both their views of marriage and their dynamics and results here should not be generalized to all such couples. We also note that cohabitation may be a unique relational status in the United States where cohabitation is still not institutionalized to the degree it is in other parts of the world (Soons \& Kalmijn, 2009). Therefore, it is likely that results of the present study may be a unique U.S. phenomenon where cohabitation is still tied to future marriage for many cohabiting couples. Finally, current measurement utilized on the RELATE assessment included limited assessments of overall marital orientation. Several scholars (see Hall, 2006) have suggested that multidimensional scales are needed to truly assess all aspects of marital beliefs. Future studies should further explore how other aspects of marital orientation, such as beliefs about future gender roles or parenting, could further enhance our understanding of this area of scholarship. As an additional measurement limitation, the specific length of cohabitation was not assessed in RELATE and may be a future variable of study for scholars.

Despite such limitations, results from the present study addressed several previous limitations and contributed several findings to this area. Results documented the presence of cross-partner effects when exploring associations between marital orientations and relational well-being among cohabiters. Results also continue to support the idea that many cohabiting couples exist within a marital context where marriage and one's orientation toward it are associated with the dynamics and quality of the relationship. As cultural norms around marriage and cohabitation continue to fluctuate, scholars should continue to monitor such associations to understand how cohabitation is situated within the larger relational life course of individuals.

\section{References}

Booth, A., Johnson, D. R., \& Edwards, J. N. (1983). Measuring marital instability. Journal of Marriage and the Family, 45, 387-394. http://dx .doi.org/10.2307/351516

Brown, S. L. (2004). Moving from cohabitation to marriage: Effects on relationship quality. Social Science Research, 33, 1-19. http://dx.doi .org/10.1016/S0049-089X(03)00036-X

Busby, D. M., Holman, T. B., \& Niehuis, S. (2009). The association between partner enhancement and self-enhancement and relationship quality outcomes. Journal of Marriage and Family, 71, 449-464. http:// dx.doi.org/10.1111/j.1741-3737.2009.00612.x

Busby, D. M., Holman, T. B., \& Taniguchi, N. (2001). RELATE: Relationship evaluation of the individual, family, cultural, and couple contexts. Family Relations, 50, 308-316. http://dx.doi.org/10.1111/j.17413729.2001.00308.x

Cook, W. L., \& Kenny, D. A. (2005). The actor-partner interdependence model: A model of bidirectional effects in developmental studies. International Journal of Behavioral Development, 29, 101-109. http://dx.doi .org/10.1080/01650250444000405
Curtin, S. C., Venture, S. J., \& Martinez, G. M. (2014). Recent declines in nonmarital childbearing in the United States. Hyattsville, MD: National Center of Health Statistics.

Goodwin, P. Y., Mosher, W. D., \& Chandra, A. (2010). Marriage and cohabitation in the United States: A statistical portrait based on Cycle 6 (2002) of the National Survey of Family Growth. Hyattsville, MD: U. S. Dept. of Health and Human Services, Centers for Disease Control and Prevention, National Center for Health Statistics.

Guzzo, K. B. (2009). Marital intentions and the stability of first cohabitations. Journal of Family Issues, 30, 179-205. http://dx.doi.org/10.1177/ 0192513 X08323694

Hall, S. S. (2006). Marital meaning: Exploring young adults' belief systems about marriage. Journal of Family Issues, 27, 1437-1458. http:// dx.doi.org/10.1177/0192513X06290036

Heuveline, P., \& Timberlake, J. M. (2004). The role of cohabitation in family formation: The United States in comparative perspective. Journal of Marriage and Family, 66, 1214-1230. http://dx.doi.org/10.1111/j $.0022-2445.2004 .00088 . x$

Huang, P. M., Smock, P. J., Manning, W. D., \& Bergstrom-Lynch, C. A (2011). He says, she says: Gender and cohabitation. Journal of Family Issues, 32, 876-905. http://dx.doi.org/10.1177/0192513X10397601

Jose, A., O'Leary, K. D., \& Moyer, A. (2010). Does premarital cohabitation predict subsequent marital stability and marital quality? A metaanalysis. Journal of Marriage and Family, 72, 105-116. http://dx.doi .org/10.1111/j.1741-3737.2009.00686.x

Kenny, D. A., \& Cook, W. (1999). Partner effects in relationship research: Conceptual issues, analytic difficulties, and illustrations. Personal Relationships, 6, 433-448. http://dx.doi.org/10.1111/j.1475-6811.1999.tb00202.x

Kline, G. H., Stanley, S. M., Markman, H. J., Olmos-Gallo, P. A., St Peters, M., Whitton, S. W., \& Prado, L. M. (2004). Timing is everything: Pre-engagement cohabitation and increased risk for poor marital outcomes. Journal of Family Psychology, 18, 311-318. http://dx.doi.org/10 .1037/0893-3200.18.2.311

Light, A., \& Omori, Y. (2013). Determinants of long-term unions: Who survives the "seven year itch"? Population Research and Policy Review, 32, 851-891. http://dx.doi.org/10.1007/s11113-013-9285-6

Manning, W. D., \& Cohen, J. A. (2012). Premarital cohabitation and marital dissolution: An examination of recent marriages. Journal of Marriage and Family, 74, 377-387. http://dx.doi.org/10.1111/j.17413737.2012.00960.x

Manning, W. D., \& Smock, P. J. (2005). Measuring and modeling cohabitation: New perspectives from qualitative data. Journal of Marriage and Family, 67, 989-1002. http://dx.doi.org/10.1111/j.1741-3737.2005 .00189.x

Murrow, C., \& Shi, L. (2010). The influence of cohabitation purposes on relationship quality: An examination in dimensions. American Journal of Family Therapy, 38, 397-412. http://dx.doi.org/10.1080/01926187 .2010 .513916

Rhoades, G. K., Stanley, S. M., \& Markman, H. J. (2009). The preengagement cohabitation effect: A replication and extension of previous findings. Journal of Family Psychology, 23, 107-111. http://dx.doi.org/ $10.1037 / \mathrm{a} 0014358$

Rusbult, C. E., \& Ximena, B. (1997). Interdependence theory. In S. Duck (Ed.), Handbook of personal relationships: Theory, research, and interventions (2nd ed., pp. 221-250). Hoboken, NJ: Wiley.

Schoen, R., Landale, N. S., \& Daniels, K. (2007). Family transitions in young adulthood. Demography, 44, 807-820. http://www.jstor.org/stable/ 30053119. http://dx.doi.org/10.1353/dem.2007.0044

Seltzer, J. A. (2004). Cohabitation in the United States and Britain: Demography, kinship, and the future. Journal of Marriage and Family, 66 , 921-928. http://dx.doi.org/10.1111/j.0022-2445.2004.00062.x

Soons, J. P. M., \& Kalmijn, M. (2009). Is marriage more than cohabitation? Well-being differences in 30 European countries. Journal of Marriage 
and Family, 71, 1141-1157. http://dx.doi.org/10.1111/j.1741-3737.2009 $.00660 . \mathrm{x}$

Stanley, S. M., \& Markman, H. J. (1992). Assessing commitment in personal relationships. Journal of Marriage and Family, 54, 595-608. http://dx.doi.org/10.2307/353245

Stanley, S. M., Rhoades, G. K., Amato, P. R., Markman, H. J., \& Johnson, C. A. (2010). The timing of cohabitation and engagement: Impact on first and second marriages. Journal of Marriage and Family, 72, 906918. http://dx.doi.org/10.1111/j.1741-3737.2010.00738.x

Stanley, S. M., Rhoades, G. K., \& Markman, H. J. (2006). Sliding versus deciding: Inertia and the premarital cohabitation effect. Family Relations, 55, 499-509. http://dx.doi.org/10.1111/j.1741-3729.2006.00418.x

Wang, J., \& Wang, X. (2012). Structural equation modeling: Applications using Mplus. United Kingdom: Wiley.

Willoughby, B. J. (2010). Marital attitude trajectories across adolescence. Journal of Youth and Adolescence, 39, 1305-1317. http://dx.doi.org/10 .1007/s10964-009-9477-x

Willoughby, B. J. (2015). The role of marital beliefs as a component of positive relationship functioning. Journal of Adult Development, 22, 76-89. http://dx.doi.org/10.1007/s10804-014-9202-1
Willoughby, B. J., Carroll, J. S., \& Busby, D. M. (2012). The different effects of "living together:" Determining and comparing types of cohabiting couples. Journal of Social and Personal Relationships, 29, 397 419. http://dx.doi.org/10.1177/0265407511431184

Willoughby, B. J., Hall, S. S., \& Luczak, H. P. (2015). Marital paradigms: A conceptual framework for marital attitudes, values, and beliefs. Journal of Family Issues, 36, 188-211. http://dx.doi.org/10.1177/ $0192513 X 13487677$

Wilson, K. L., Charker, J., Lizzio, A., Halford, K., \& Kimlin, S. (2005). Assessing how much couples work at their relationship: The behavioral self-regulation for effective relationships scale. Journal of Family Psychology, 19, 385-393. http://dx.doi.org/10.1037/0893-3200.19.3.385

Received February 13, 2015

Revision received July 29, 2015

Accepted July 29, 2015

\section{Members of Underrepresented Groups: Reviewers for Journal Manuscripts Wanted}

If you are interested in reviewing manuscripts for APA journals, the APA Publications and Communications Board would like to invite your participation. Manuscript reviewers are vital to the publications process. As a reviewer, you would gain valuable experience in publishing. The $\mathrm{P} \& \mathrm{C}$ Board is particularly interested in encouraging members of underrepresented groups to participate more in this process.

If you are interested in reviewing manuscripts, please write APA Journals at Reviewers@apa.org. Please note the following important points:

- To be selected as a reviewer, you must have published articles in peer-reviewed journals. The experience of publishing provides a reviewer with the basis for preparing a thorough, objective review.

- To be selected, it is critical to be a regular reader of the five to six empirical journals that are most central to the area or journal for which you would like to review. Current knowledge of recently published research provides a reviewer with the knowledge base to evaluate a new submission within the context of existing research.

- To select the appropriate reviewers for each manuscript, the editor needs detailed information. Please include with your letter your vita. In the letter, please identify which APA journal(s) you are interested in, and describe your area of expertise. Be as specific as possible. For example, "social psychology" is not sufficient—you would need to specify "social cognition" or "attitude change" as well.

- Reviewing a manuscript takes time (1-4 hours per manuscript reviewed). If you are selected to review a manuscript, be prepared to invest the necessary time to evaluate the manuscript thoroughly.

APA now has an online video course that provides guidance in reviewing manuscripts. To learn more about the course and to access the video, visit http://www.apa.org/pubs/authors/reviewmanuscript-ce-video.aspx. 